\title{
Seminal Vesicle
}

National Cancer Institute

\section{Source}

National Cancer Institute. Seminal Vesicle. NCI Thesaurus. Code C12787.

One of the two paired glands in the male genitourinary system, posterior to the bladder and superior to the prostate gland, that produces fructose-rich seminal fluid which is a component of semen. These glands join the ipsilateral ductus deferens to form the ejaculatory duct. 